\title{
INDIVIDUALISMO E COLECTIVISMO: FUNDAMENTOS CONCEPTUAIS PARA O ESTUDO INTERCULTURAL DAS CONCEPÇÕES PESSOAIS DE INTELIGÊNCIA DE ESTUDANTES PORTUGUESES E ROMENOS
}

\author{
Laura Ciochină ${ }^{1}$ \\ Luisa Faria ${ }^{2}$
}

Resumo: A questão-chave do presente artigo centra-se na tentativa de evidenciar o modo como a dimensão de individualismo-colectivismo (IND/COL) - que, nos últimos 20 anos, tem sido preponderantemente utilizada para comparar as sociedades - pode ser operacionalizada, com o objectivo de se conceber uma metodologia adequada para medir e validar estes dois constructos tão controversos e, consequentemente, para indagar a sua relação com aspectos psicológicos do comportamento dos indivíduos, particularmente no que se refere à estruturação e ao desenvolvimento das concepções pessoais de inteligência (CPI). Deste modo, a um nível teórico, analisa-se a influência do IND/COL nas CPI de estudantes portugueses e romenos, partindo do pressuposto de que o contexto cultural em que os indivíduos vivem e agem modela tais concepções e, implicitamente, influencia os respectivos padrões de realização e de desempenho escolar.

Palavras-chave: individualismo-colectivismo, concepções pessoais de inteligência, cultura.

Individualism and Collectivism: Conceptual Basis for the Intercultural Study of Personal Conceptions of Intelligence of Portuguese and Romanian Students (Abstract): The core aspect of this article is centered on the attempt of highlighting the way in which the individualism-collectivism (IND/COL) dimension - which in the last 20 years has been largely used to compare societies - can be accurately operacionalized, to conceive an adequate methodology for the measurement and validation of these two controversial constructs, and, consequently, for the investigation of their relation with individuals' psychological aspects of behavior,

\footnotetext{
${ }^{1}$ Doutoranda em Psicologia na Faculdade de Psicologia e de Ciências da Educação da Universidade do Porto (FPCEUP); bolseira de doutoramento pela Fundação para a Ciên-

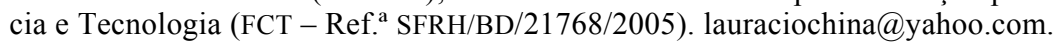

2 Professora Associada com Agregação da FPCEUP. lfaria@fpce.up.pt. Faculdade de Psicologia e de Ciências da Educação, Universidade do Porto, Rua Dr. Manuel Pereira da Silva, s/n - 4200-392 Porto.
} 
particularly, with the structuring and the development of personal conceptions of intelligence (PCI). In this way, at a theoretical level, we explore the influence of the IND/COL on the PCI of Portuguese and Romanian students, proceeding from the assumption that the cultural context, in which individuals live and act, models such conceptions, and, implicitly, influences the respective achievement patterns of behavior and school performance.

Keywords: individualism-collectivism, personal conceptions of intelligence, culture.

\section{Processos psicológicos e contexto cultural: Estado da arte}

A preocupação com a diversidade cultural no desenvolvimento psicológico dos indivíduos, particularmente no seu funcionamento cognitivo e nos modos de relacionamento interpessoal, tem conduzido a um incremento notável no que se refere às abordagens e aos estudos interculturais realizados no domínio da Psicologia. Os resultados de tal linha de investigação representam um contra-argumento quase irrefutável à concepção, ainda amplamente partilhada, de que as estruturas e os processos psicológicos se desenvolvem e evoluem independentemente do contexto cultural a que pertencem, uma vez que tem vindo a ser assumido que "as experiências socioculturais, vistas como necessárias para o desenvolvimento humano normal, são universais e conduzem a resultados universais" (Miller, 1999, p. 87).

$\mathrm{Na}$ verdade, investigações recentes no domínio da Psicologia Cultural, particularmente os estudos na área da cognição social, desafiam tal concepção, tendo demonstrado que o comportamento humano depende dos significados que os indivíduos atribuem às experiências vividas. Ora, se os processos psicológicos superiores são influenciados pelas interpretações dos indivíduos acerca das suas experiências de vida, e se tais interpretações reflectem e dependem, basicamente, dos significados, das práticas, das regras, das instituições, das tradições e dos valores culturais, isto pode significar que a cultura modela o funcionamento psicológico dos indivíduos.

Assim, é de referir que os resultados que têm sido obtidos na área da cognição social foram precedidos pelos trabalhos realizados no âmbito da tradição sociocultural - tendo Vygotsky (1896-1934/1978) como um dos seus mais importantes promotores -, tradição esta que considera que o pensamento lógico é basicamente estruturado pelas actividades concretas em que o indivíduo está envolvido e pelos instrumentos culturais nos quais tal pensamento está ancorado.

Por sua vez, no domínio da investigação em Psicologia Social, os psicólogos encaram o processo de construção das representações sociais, colocando um importante enfoque no indivíduo, enquanto sujeito activo, criati- 
vo, mas sempre situado num contexto cultural-ideológico (Mugny \& Carugati, 1985): neste sentido, tal como considera Neculau (1996), "o indivíduo, através da sua biografia, é prisioneiro do seu contexto cultural” (p. 36).

Os exemplos acima apresentados, que salientam o papel dos factores culturais na emergência e no desenvolvimento dos processos psicológicos, resultam de investigações que estudam um determinado fenómeno psicológico dentro de apenas uma cultura, mas esta situação foi ultrapassada no domínio da Psicologia, pois as abordagens interculturais têm sido particularmente estimuladas, nomeadamente pelo importante trabalho de Hofstede (1980) acerca de valores ligados ao trabalho em sessenta e seis países. A partir deste estudo, Hofstede estabeleceu quatro dimensões que considera poderem explicar grande parte das diferenças existentes entre culturas: a distância hierárquica, o individualismo-colectivismo (IND/COL), a masculinidade-feminilidade e o controlo da incerteza. Embora estejam todas relacionadas entre si, a dimensão de IND/COL recebeu grande parte da atenção dos investigadores que prosseguiram o trabalho de Hofstede, pelo que se exige a análise das especificidades dos dois constructos e a sua abordagem no âmbito dos estudos de Psicologia Intercultural.

\section{IND/COL - breve história}

Actualmente, ser individualista parece ser equivalente, principalmente, a ser americano, no entanto, a referência ao individualismo parece ter tido origem na Revolução Francesa (Oyserman, Coon \& Kemmelmeier, 2002), pois, na visão ideológica daquele tempo, o termo individualismo era utilizado para enfatizar a influência perniciosa dos direitos individuais no bem-estar da comunidade e da sua estrutura social.

Mais concretamente, a tradição ocidental, na área da Sociologia, no que se refere à distinção entre os enfoques individualista e colectivista, apoia-se na necessidade de estudar o comportamento social "de uma maneira universal" (Triandis, 1994, p. 15), logo, na perspectiva deste autor, isto significa investigar a maioria dos seres humanos, no contexto de várias culturas, sendo necessário, em algumas delas, enfatizar os grupos sociais, enquanto noutras a ênfase será no indivíduo.

A título de exemplo, refira-se que Durkheim (1887/1933, in Oyserman et al., 2002) distingue a solidariedade orgânica - ilustrativa do pólo individualista e dependente de relações temporárias, constituídas no seio de sociedades complexas, entre indivíduos diferentes uns dos outros - da solidariedade mecânica - ilustrativa do pólo colectivista e dependente de relações permanentes, constituídas nas sociedades tradicionais, entre indivíduos semelhantes, e que Mead (1967, in Triandis, Bontempo, Villareal, Asai \& Lucca, 1988) considera que as culturas se diferenciam em função do grau de 
cooperação ou de competição entre os seus indivíduos, sendo a dimensão cultural resultante a de cooperação-individualismo, cujo corolário, a nível individual, é o alocentrismo-idiocentrismo (Triandis, McCusker \& Hui, 1990).

Outros autores utilizaram uma terminologia diferente, veiculando, contudo, o mesmo universo de significação: o self independente vs. o self interdependente (Markus \& Kitayama, 1991, in Triandis, 1994), o self privado vs. o self colectivo (Trafimow, Triandis \& Goto, 1991), o preço de mercado (market pricing) vs. a partilha comunitária (communal sharing) (Fiske, 1992, in Fiske, 2002) ou Gemeinschaft (comunidade) vs. Gesellschaft (sociedade) (Tönnies, 1887/1957, in Oyserman et al., 2002).

Assim, este quadro de pesquisa tem gerado modelos conceptuais e sistemas teóricos acerca dos constructos de IND/COL, apontando para o seu estatuto de dimensão essencial de variação cultural dentro do campo de investigação da Psicologia Cultural e Intercultural: de facto, nos últimos 20 anos, os investigadores têm utilizado abundantemente a diferenciação entre individualismo e colectivismo (e não outra qualquer), a fim de contrastar as sociedades estudadas, na senda da investigação de Hofstede (1980) anteriormente referida, cujo contributo vamos analisar mais detalhadamente.

\section{IND/COL na investigação de Hofstede}

$\mathrm{Na}$ qualidade de sociólogo organizacional e investigador da IBM, Hofstede teve a oportunidade de estudar um significativo conjunto de dados sobre valores ligados ao trabalho, que foram obtidos a partir de amostras estratificadas e equivalentes de trabalhadores da IBM, em mais de 40 países (dos iniciais 66 previstos para a realização do estudo). O questionário utilizado tinha 32 itens, considerados por Hofstede como representativos de valores ou objectivos ligados ao trabalho. As análises estatísticas realizadas apontaram para a existência de quatro dimensões culturais, já referidas por nós anteriormente (individualismo-colectivismo, distância hierárquica, masculinidade-feminilidade e controlo da incerteza). Deste modo, a partir dos resultados encontrados para estas dimensões nos diferentes países, Hofstede construiu uma tipologia para 40 nações do mundo, partindo da sua posição nestas quatro dimensões culturais.

Bond (2002) considera que esta tipologia teve, e ainda tem, um valor empírico de suporte para os psicólogos interculturais, especialmente para os que partem do pressuposto de que as amostras utilizadas são representativas das nações investigadas. A este respeito, o mesmo autor salienta que a dimensão mais tomada em consideração foi a do individualismo-colectivismo, particularmente por causa do seu histórico nas ciências sociais. 
De facto, Hofstede (1980) considera que uma das origens das diferenças existentes entre culturas é representada pelo papel do indivíduo ou do grupo no desenvolvimento das sociedades humanas. Partindo deste pressuposto, e com base em resultados de investigações de Antropologia Social, Hofstede salienta que a maioria dos indivíduos do nosso planeta vive em sociedades caracterizadas pela prevalência dos interesses do grupo sobre os interesses do indivíduo, sociedades essas denominadas colectivistas. Em tais sociedades, o grupo de pertença oferece protecção ao indivíduo, em troca da sua lealdade: entre o grupo de pertença e o indivíduo constrói-se e desenvolve-se uma relação de interdependência, de tal modo que o indivíduo define a sua identidade em termos que remetem para a especificidade e para a vida do grupo. Em sentido contrário, uma minoria de habitantes do planeta vive em sociedades onde o indivíduo representa a principal unidade de percepção e análise social, prevalecendo os seus interesses sobre os do grupo. Trata-se, então, das denominadas sociedades individualistas, nas quais existe uma relação de independência do indivíduo face ao grupo, definindo o indivíduo a sua identidade a partir das suas características pessoais.

De referir, ainda, que Hofstede (1980) utilizou as designações IND/COL para descrever as relações de dependência $v s$. independência do indivíduo face ao grupo de pertença, embora, mais concretamente, no que se refere ao seu questionário sobre os valores ligados ao trabalho, a dimensão de individualismo se tenha apresentado mais fortemente associada à importância relativa atribuída pelos sujeitos ao tempo pessoal, à liberdade e ao desafio, enquanto que a formação, as condições de trabalho e a utilização de competências constituíram a dimensão de colectivismo: Bond (2002) considera que os três primeiros valores, com os respectivos objectivos motivacionais subjacentes, estão, obviamente, relacionados com o individualismo, encarado nas ciências sociais como um constructo multifacetado, enquanto que os últimos três valores descrevem, de um modo mais duvidoso, o colectivismo. Assim, na tentativa de esclarecer e alargar o âmbito conceptual dos dois constructos (IND/COL), vários investigadores continuaram os trabalhos de Hofstede, estabelecendo definições operacionais e concebendo vários métodos para avaliar o IND/COL, como a seguir apresentamos.

\section{IND/COL - caracterização}

\section{Individualismo}

O núcleo central do individualismo é representado pelo facto de os indivíduos serem independentes uns dos outros. Na descrição conceptual desta dimensão cultural, Hofstede enfatiza a prevalência dos direitos sobre 
as obrigações, a preocupação com a própria pessoa e a família imediata, a autonomia pessoal e a auto-realização, logo, a construção da identidade pessoal, tendo como ponto de partida os méritos, os atributos e as realizações pessoais.

Triandis e colaboradores (1988) completam este quadro descritivo, enfatizando o tipo de relação do indivíduo com o in-grupo, salientando que, nas culturas individualistas, existem vários in-grupos - por exemplo, a família, o grupo de trabalho e os clubes, definidos pelos autores como conjuntos de pessoas com quem se partilha um determinado atributo -, que fornecem uma identidade social positiva, sendo o comportamento do indivíduo modelado pelos objectivos de cada um destes grupos. Contudo, não se pode deixar de salientar o facto de as relações do indivíduo com um determinado in-grupo não serem estáveis (ao contrário do que acontece nas culturas colectivistas), nomeadamente porque o indivíduo pode deixar o in-grupo, caso este já não sirva os seus interesses pessoais.

Por sua vez, Schwartz (1990, in Schwartz, 1992) considera que as sociedades individualistas são sociedades contratuais, consistindo em grupos primários, de dimensões reduzidas, grupos estes que comportam um tipo de relações sociais em que, através de negociações, as pessoas abordam as suas obrigações, de tal modo que possam obter ou modificar um determinado estatuto social.

\section{Colectivismo}

Já o núcleo central do colectivismo é representado pela relação de dependência do indivíduo face ao grupo de pertença. Segundo Schwartz (1990, in Oyserman et al., 2002), as sociedades colectivistas são caracterizadas por obrigações mútuas e difusas, tendo os indivíduos estatutos preestabelecidos que não podem modificar. Quanto ao tipo de relação do indivíduo com o grupo de pertença, Triandis (1994) e Triandis et al. (1988) salientam que se trata de uma relação estável, na qual os interesses e os objectivos dos indivíduos se subordinam aos do grupo. De referir, ainda, que o indivíduo não pode abandonar o in-grupo, mesmo que os custos que decorrem desta pertença sejam maiores do que os respectivos benefícios.

\section{IND/COL - métodos de avaliação}

A partir das definições conceptuais do IND/COL, vários investigadores, na área da Psicologia Cultural e Intercultural, que não se limitaram a tomar à letra os índices de IND/COL estabelecidos por Hofstede, concebe- 
ram diferentes técnicas para avaliar esta dimensão cultural e, consequentemente, para indagar o seu impacto sobre vários processos psicossociais.

Assim, na sua meta-análise da literatura produzida no últimos 20 anos sobre a dimensão de IND/COL, Oyserman e colaboradores (2002) alocam um espaço significativo às escalas até agora construídas para medir o IND/COL, devido à sua prevalência no contexto de outros tipos de métodos utilizados na avaliação dos referidos constructos. De facto, não existindo um instrumento estandardizado ou consensual, Oyserman et al. (2002) sistematizaram as escalas encontradas em categorias compreensivas, resultando de tal trabalho 27 escalas distintas. De referir, ainda, que, nestas escalas, umas abordam o IND/COL como um constructo único de natureza bipolar (medindo, portanto, o maior ou menor grau de individualismo vs. colectivismo), enquanto outras tratam o IND/COL como constructos ortogonais (avaliando, portanto, o individualismo e o colectivismo).

Ora, Schwartz (1994, in Oyserman et al., 2002) considera esta segunda abordagem mais adequada, avançando a hipótese de que, dentro de cada sociedade, existem representações de ambas as visões, individualista e colectivista, sendo o enfoque colocado nos respectivos atributos característicos.

Refira-se, ainda, que os autores das escalas, em alguns casos, estabeleceram também subescalas, tal como Triandis e colaboradores (1988), que identificaram três dimensões no IND/COL, a saber: Auto-Suficiência com Competição, Preocupação com o In-grupo - constituída por itens pertencentes à Escala de Colectivismo-Individualismo de Hui (1988, in Shulruf, Hattie \& Dixon, 2003) - e Distância do In-grupo.

Voltando à análise das referidas 27 escalas, saliente-se que Oyserman e colaboradores (2002) identificaram sete domínios principais ligados ao IND e oito ligados ao COL (ver Quadro 1). Na verdade, a maioria dos estudos, segundo os autores, relacionaram o individualismo com a valorização da independência, mas outros domínios, tais como as realizações pessoais, a unicidade e a comunicação directa foram também muito utilizados. Por sua vez, quanto ao colectivismo, a maioria dos estudos vai relacioná-lo com as obrigações face ao grupo, as relações com os outros, a procura dos conselhos dos outros, a harmonia e o trabalho em grupo.

Sintetizando, das observações realizadas por Oyserman et al. (2002), através da análise de conteúdo das 27 escalas de IND/COL, pode destacar-se o carácter consensual das operacionalizações produzidas pelos investigadores para ambos os constructos, de tal modo que a independência pessoal é unanimemente considerada como elemento-chave do individualismo, enquanto que a subordinação do indivíduo, dos seus objectivos e dos seus interesses pessoais ao grupo de pertença representa o elemento univocamente considerado como essencial e ilustrativo do colectivismo. 
Quadro 1 - Domínios avaliados pelas Escalas de Individualismo-Colectivismo

\begin{tabular}{|c|c|c|}
\hline Domínio & Descrição & Exemplos de itens \\
\hline \multicolumn{3}{|l|}{ Individualismo: } \\
\hline Independência & $\begin{array}{l}\text { Liberdade, auto-suficiên- } \\
\text { cia, controlo sobre a pró- } \\
\text { pria vida. }\end{array}$ & $\begin{array}{l}\text { 'Tendo a preocupar-me } \\
\text { com as minhas coisas e } \\
\text { também com a minha } \\
\text { família'. }\end{array}$ \\
\hline Objectivos & $\begin{array}{l}\text { Realização de esforços } \\
\text { para alcançar os objecti- } \\
\text { vos pessoais. }\end{array}$ & $\begin{array}{l}\text { 'Gosto de realizar o que os } \\
\text { outros não conseguem'. }\end{array}$ \\
\hline Competição & $\begin{array}{l}\text { Ambição pessoal, desafio } \\
\text { e sucesso. }\end{array}$ & $\begin{array}{l}\text { 'Para mim, é importante } \\
\text { realizar melhor do que os } \\
\text { outros'. }\end{array}$ \\
\hline Unicidade & $\begin{array}{l}\text { Enfoque na sua indivi- } \\
\text { dualidade e nas suas qua- } \\
\text { lidades idiossincráticas. }\end{array}$ & $\begin{array}{l}\text { 'Sou único(a)/diferente dos } \\
\text { outros sob muitos aspec- } \\
\text { tos'. }\end{array}$ \\
\hline Privacidade & $\begin{array}{l}\text { Pensamentos e acções } \\
\text { privadas. }\end{array}$ & $\begin{array}{l}\text { 'Gosto da minha privaci- } \\
\text { dade'. }\end{array}$ \\
\hline $\begin{array}{l}\text { Conhecimento de si } \\
\text { mesmo }\end{array}$ & $\begin{array}{l}\text { Conhecer-se a si mesmo, } \\
\text { ter uma identidade forte. }\end{array}$ & $\begin{array}{l}\text { 'Conheço os meus pontos } \\
\text { fortes e as minhas fraque- } \\
\text { zas'. }\end{array}$ \\
\hline Comunicação directa & $\begin{array}{l}\text { Expressão clara dos seus } \\
\text { desejos e necessidades. }\end{array}$ & $\begin{array}{l}\text { 'Exprimo sempre as } \\
\text { minhas opiniões de uma } \\
\text { maneira clara'. }\end{array}$ \\
\hline Domínio & Descrição & Exemplos de itens \\
\hline
\end{tabular}

Colectivismo:

Relações com os outros Os outros próximos são considerados como parte integrante de si mesmo.

Sentido de pertença
Vontade de pertencer e gostar de ser parte integrante do grupo.
'Para entender quem sou, têm que me ver com os membros do meu grupo'.

'Para mim, prazer significa passar tempo com os outros'. 


\begin{tabular}{|c|c|c|}
\hline Domínio & Descrição & Exemplos de itens \\
\hline Obrigações & $\begin{array}{l}\text { A pertença ao grupo } \\
\text { implica obrigações e } \\
\text { sacrifícios. }\end{array}$ & $\begin{array}{l}\text { 'Se um familiar me disses- } \\
\text { se que tinha problemas } \\
\text { económicos, ajudá-lo-ia, } \\
\text { de acordo com as minhas } \\
\text { possibilidades'. }\end{array}$ \\
\hline Harmonia & $\begin{array}{l}\text { Preocupação com a har- } \\
\text { monia do grupo e o bom } \\
\text { entendimento entre os } \\
\text { seus membros. }\end{array}$ & $\begin{array}{l}\text { 'Faço esforços para evitar } \\
\text { as discórdias com mem- } \\
\text { bros do meu grupo'. }\end{array}$ \\
\hline Conselho & $\begin{array}{l}\text { Pedido de ajuda a outros } \\
\text { próximos para tomar } \\
\text { decisões. }\end{array}$ & $\begin{array}{l}\text { 'Antes de tomar uma deci- } \\
\text { são, consulto sempre } \\
\text { outras pessoas'. }\end{array}$ \\
\hline Contexto & $\begin{array}{l}\text { Modificações do self } \\
\text { dependentes do contexto } \\
\text { ou da situação exterior. }\end{array}$ & $\begin{array}{l}\text { 'O meu comportamento } \\
\text { depende da pessoa com } \\
\text { quem estou, do lugar onde } \\
\text { estou ou de ambas as situa- } \\
\text { ções'. }\end{array}$ \\
\hline Hierarquia & $\begin{array}{l}\text { Enfoque na hierarquia e } \\
\text { em questões ligadas ao } \\
\text { estatuto. }\end{array}$ & $\begin{array}{l}\text { 'Respeito as autoridades } \\
\text { com que contacto'. }\end{array}$ \\
\hline Grupo & $\begin{array}{l}\text { Preferência pelo trabalho } \\
\text { em grupo. }\end{array}$ & $\begin{array}{l}\text { 'Prefiro o trabalho em } \\
\text { grupo ao trabalho indivi- } \\
\text { dual'. }\end{array}$ \\
\hline
\end{tabular}

Nota: Adaptado de Oyserman et al. (2002).

Contudo, mesmo que não se questione o consenso científico acerca da operacionalização dos dois constructos (individualismo-colectivismo), a validade das escalas destinadas à respectiva avaliação e os limites que estas comportam não deixam de constituir um problema: Fiske (2002) considera que um dos principais limites das escalas e dos questionários utilizados para avaliar a dimensão cultural de IND/COL está relacionado com um problema de cariz epistemológico, pois estes instrumentos implicam conteúdos verbais, orais ou escritos, de tal modo que as escalas de avaliação e, até, as de resposta livre e as entrevistas, através dos dados que recolhem, sugerem que a cultura representa um conjunto de conhecimentos "declarativos", "semânticos" ou "episódicos" (Fiske, 2002, p. 81).

Ora, investigações mais recentes, acrescenta o mesmo autor, mostram que os elementos de uma cultura, tais como as práticas e as competências, 
os valores e as regras, os sistemas motivacionais e as emoções, os símbolos e os artefactos escapam à reflexão consciente, sendo, portanto, dificilmente expressos através da linguagem verbal, oral ou escrita, em que se funda o auto-relato.

Assim, uma vez que o elemento axial de uma cultura reside em "competências procedimentais e não em proposições abstractas" (Fiske, 2002, p. 82), a solução radical proposta por Fiske, como método alternativo, é o da observação participante (método não muito compatível com as exigências das investigações realizadas em Psicologia), a par de entrevistas, histórias de vida, testes projectivos, cenários (que tentam reproduzir situações reais de vida, com um determinado conteúdo normativo, a fim de avaliar as atitudes dos indivíduos face a tais situações em diferentes tipos de culturas), no âmbito da colaboração entre investigadores de diferentes culturas, a fim de captar os conhecimentos implícitos, as competências, as práticas e os valores dos contextos culturais estudados.

Esta questão dos métodos alternativos ou, de facto, complementares, será retomada mais à frente. Na verdade, embora controversas e muito criticadas, as escalas continuam a ter supremacia nos estudos que têm como objectivo avaliar os dois constructos (IND/COL) e investigar a sua relação com diferentes processos psicossociais.

A dimensão de individualismo-colectivismo tem sido frequentemente utilizada em estudos de comparação intercultural, estudos esses, na sua maioria, correlacionais (que não avaliaram, mas sim, apenas invocaram o IND/ COL), com o objectivo de testar e de explicar algumas teorias e conceptualizações centrais na Psicologia, como o self, enquanto ligação, na perspectiva de Somech (2000), entre o nível cultural (macro) e o nível individual (micro), a auto-estima e outros processos de avaliação pessoal (Heine \& Lehman, 1995; Heine, Kitayama \& Lehman, 2001; Kitayama, Markus, Matsumoto \& Norasakkunit, 1997), o estilo atribucional (Choi \& Nisbett, 1998) ou o estilo comunicacional (Kapoor, Hughes Baldwin \& Blue, 2003).

Por sua vez, ainda existem autores que avançam a hipótese de que as diferenças culturais encontradas em estudos que investigam a percepção de vários atributos, ligados à própria pessoa, aos outros e a outros aspectos exteriores ao self, possam resultar de diferenças culturais, nas teorias implícitas subjacentes a tais percepções (Church, Ortiz, Katigbak, Avdeyeva, Emerson, Flores \& Reyes, 2003), diferenças essas que, na sua maioria, são discutidas à luz das especificidades da já referida dimensão de individualismo-colectivismo.

Ora, no quadro das teorias implícitas, e a propósito das concepções pessoais de inteligência (CPI), que representam o segundo eixo de análise do presente artigo, é de referir que não têm existido preocupações sistemáticas na realização de comparações interculturais, embora, por exemplo, no 
domínio da Educação, haja uma grande tradição na comparação do desempenho escolar de alunos de vários países, que pode ser influenciado pelas suas concepções pessoais de inteligência.

Assim, antes de se referir o modo como tal ausência de estudos interculturais, no que se refere às CPI, foi ultrapassada, apresentaremos o modelo teórico das CPI proposto por Dweck (1999).

\section{Concepções pessoais de inteligência - modelo teórico de Dweck}

Na fase inicial da construção deste modelo, Bandura e Dweck (1985) partem de uma série de observações, realizadas no contexto escolar, relativas às crenças que os alunos têm sobre a sua inteligência, identificando dois tipos principais: o primeiro apresenta a inteligência como algo que gera ansiedade e preocupação, pois a inteligência é concebida como uma "quantidade" limitada, que pode ou não ser suficiente, de tal modo que a representação resultante de tal posicionamento face à própria inteligência é que não se pode fazer muito para desenvolver este atributo psicológico; o segundo tipo, por sua vez, apresenta a inteligência como algo que pode ser desenvolvido através do esforço e do investimento pessoal, uma vez que não se trata de uma "quantidade incontrolável", mas sim de uma "qualidade flexível", logo, susceptível de ser modificada e desenvolvida.

Tomando como ponto de partida esta dicotomia na representação da natureza da inteligência, Bandura e Dweck (1985) identificaram e enquadraram num modelo teórico as duas concepções ou teorias adoptadas pelos alunos: a este respeito, saliente-se que Faria (2003) constata a pertinência conceptual do termo "teoria", utilizado acerca das concepções pessoais de inteligência, considerando que, deste modo, se consegue transmitir a ideia de que os alunos têm uma percepção relativamente sistemática e coerente acerca da natureza da sua própria inteligência.

Assim, a primeira destas teorias, designada concepção estática, envolve a crença de que a inteligência é uma entidade concreta, "condenada" a ser imutável, estável, logo, limitada em quantidade e incontrolável: a preocupação dos indivíduos que adoptam esta concepção reside na demonstração do seu potencial intelectual, nomeadamente pela prossecução de objectivos centrados no resultado, objectivos estes que são mais susceptíveis de conduzirem a padrões de realização de desistência (Dweck, 1999; Elliott \& Dweck, 1988; Elliott \& Harackiewicz, 1996).

Por sua vez, a segunda das teorias, designada concepção dinâmica, sublinha a centralidade da crença de que a inteligência representa um conjunto dinâmico e controlável de competências que o indivíduo pode desen- 
volver através do esforço e do investimento pessoais. Esta concepção promove a adopção pelos indivíduos de objectivos centrados na aprendizagem, objectivos esses que estão relacionados com a prossecução de padrões de realização de persistência (Dweck, 1999; Elliott \& Harackiewicz, 1996).

Sintetizando, no Quadro 2, apresenta-se o modelo de Dweck, tendo em consideração o modo como a inteligência, os objectivos, o sucesso e o fracasso são definidos pelas duas concepções pessoais (estática vs. dinâmica) de inteligência.

Quadro 2 - Modelo das Concepções Pessoais de Inteligência (Dweck, 1999)

\begin{tabular}{lll}
\hline $\begin{array}{l}\text { Concepções Pessoais } \\
\text { de Inteligência }\end{array}$ & Estática & Dinâmica \\
\hline Inteligência & $\begin{array}{l}\text { Entidade imutável, concreta; } \\
\text { traço global, estável, limita- } \\
\text { do em quantidade e incon- } \\
\text { trolável. }\end{array}$ & $\begin{array}{l}\text { Conjunto dinâmico de } \\
\text { competências que o indi- } \\
\text { víduo pode controlar e } \\
\text { desenvolver. }\end{array}$ \\
Centrados no resultado. & $\begin{array}{l}\text { Centrados na aprendiza- } \\
\text { gem. }\end{array}$ \\
Sucesso & $\begin{array}{l}\text { Procurado, para demonstrar } \\
\text { e validar a competência. }\end{array}$ & $\begin{array}{l}\text { Procurado, para desenvol- } \\
\text { ver a competência. }\end{array}$ \\
Fracasso & $\begin{array}{l}\text { Evitado, sendo considerado } \\
\text { como indicador de incompe- } \\
\text { tência. }\end{array}$ & $\begin{array}{l}\text { Aceite, sendo considerado } \\
\text { como fonte de informaçóes } \\
\text { úteis para a aprendizagem } \\
\text { e um desempenho futuro } \\
\text { melhorado. }\end{array}$ \\
& & \\
\hline
\end{tabular}

Refira-se, ainda, a perspectiva integradora de Faria (1996), que vai no sentido de apresentar as concepções pessoais de inteligência como sistemas de crenças e representações acerca da inteligência e do seu carácter evolutivo, crenças e representações estas que, através das suas especificidades e implicações cognitivo-afectivas, estruturam e orientam as acções dos indivíduos em contextos em que o papel da inteligência é determinante.

De facto, tal como evidencia Dweck (1999), investigar os dois tipos de concepções pessoais de inteligência e a sua relação com objectivos de realização particulares - que visam validar a sua própria competência $v s$. desenvolvê-la pela aprendizagem - poderá facilitar e incentivar a compreensão dos padrões de realização dos indivíduos, bem como possibilitar o desenvolvimento de estratégias de intervenção para promover a motivação 
para a aprendizagem dos alunos, agindo sobre comportamentos, objectivos e concepções, num sentido mais adaptativo.

Ora, as concepções pessoais de inteligência "mais adaptativas" deverão permitir responder, de um modo mais eficaz, a determinadas exigências dos contextos em que operam, sendo, ao mesmo tempo, influenciadas pela especificidade de tais contextos. Concretizando, a um nível mais específico, trata-se de responder e de agir no quadro do contexto escolar e, a um nível mais geral, trata-se de lidar e de operar na complexidade do contexto cultural. Esta imagem de dois contextos interdependentes, em que a inteligência aparece como atributo psicológico socialmente relevante, é ilustrada por Faria (2002), que considera que o desenvolvimento da inteligência "requer a incorporação das normas e dos valores sociais que determinam os critérios de sucesso ou de fracasso, bem como a distribuição de reforços ou de punições, não podendo, portanto, ser concebida independentemente dos valores sociais e dos objectivos da cultura, em geral, e da escola, em particular" (p. 102).

Deste modo, parece-nos importante começar por, numa primeira fase, explorar e ancorar conceptualmente a influência do contexto cultural nas concepções pessoais de inteligência, considerando como coordenada cultural a já referida dimensão de IND/COL, como passamos a apresentar.

\section{Importância do individualismo-colectivismo nas CPI}

O estudo realizado por Faria, Pepi e Alesi (2004), com estudantes portugueses e italianos, constitui um primeiro contributo para quebrar o "silêncio científico" em que se encontrava a realização de comparações interculturais quanto às CPI, consideradas na perspectiva de Dweck (1999) e de Faria $(1996,2002)$.

E, na explicação das diferenças observadas no seu estudo intercultural, as autoras também invocaram a dimensão de individualismo-colectivismo, uma vez que Portugal e a Itália fazem parte de culturas ocidentais individualistas, "apresentando sistemas sociais e educativos marcados pela pressão competitiva e pela luta individual pelo sucesso e pela excelência" (Faria, Pepi \& Alesi, 2004, p. 47), apesar de se distinguirem pelas respectivas especificidades socioculturais.

A propósito, refira-se que a fundamentação teórica em que se baseiam os estudos interculturais, tal como o de Faria e colaboradores (2004), é ancorada no facto de que, em diferentes culturas, o processo de socialização é realizado através de práticas diferenciadas, práticas essas que oferecem aos indivíduos diversas grelhas de leitura da realidade, gerando um sistema de crenças, valores, regras e normas culturalmente definidos. Não é, 
portanto, de estranhar que indivíduos de diferentes culturas valorizem de maneira diversa atributos socialmente relevantes - tais como a inteligência e o comportamento de realização -, logo, também os respectivos resultados específicos - o sucesso e o fracasso (Salili, 1994).

Assim sendo, nos contextos culturais ocidentais, como é o caso dos dois países implicados no referido estudo, o modelo mais individualista de vida, que enfatiza a liberdade pessoal, a auto-realização e a competência, a identidade e a satisfação fundadas em realizações pessoais, faz com que o sucesso seja atribuído a características individuais, tais como a inteligência, a mestria, o investimento e o esforço pessoais (Heine, Kitayama \& Lehman, 2001; Henderson, Marx \& Kim, 1999). Por sua vez, no caso das culturas mais colectivistas, em que o trabalho em grupo é privilegiado em detrimento da acção individual, a coesão do grupo realiza-se pela cooperação entre os indivíduos e através de relações de interdependência e de encorajamento colectivo, sendo o sucesso encarado como dependente não de atributos individuais, mas sim da pertença a grupos e instituições sociais (Triandis, McCusker \& Hui, 1990).

Ora, os resultados do estudo realizado por Faria, Pepi e Alesi (2004) apontam, entre outras, para a existência de diferenças relativamente às CPI de estudantes portugueses e italianos, em função da variável independente de IND/COL, constituindo-se, deste modo, num incentivo para futuras investigações que enfatizem e aprofundem o estudo da relação IND/COL-CPI, em vários contextos culturais.

\section{Resultados preliminares de um estudo com estudantes portugueses e romenos}

$\mathrm{Na}$ verdade, em primeiro lugar, pretende-se explorar as possibilidades de construção de métodos melhor adequados para avaliar a dimensão de individualismo-colectivismo, para depois analisar, de um ponto de vista teórico, a sua influência nas concepções pessoais de inteligência, em dois contextos culturais distintos: Portugal e Roménia.

Tal como foi precisado num estudo anterior de Ciochină e Faria (2006), a lógica que fundamenta a escolha dos dois contextos culturais, português e romeno, está ligada ao facto de ambos os países serem latinos e terem passado por um regime de ditadura, embora de cariz diferente (fascismo em Portugal e comunismo na Roménia), que conduziu, através de mecanismos ideológicos, políticos, culturais e sociais, à estruturação e implementação de uma mentalidade colectivista. $\mathrm{Na}$ verdade, tal como refere Hofstede (1980), em alguns países ocidentais, o termo "colectivismo" é geralmente utilizado para descrever sistemas políticos como o da antiga União Soviética. Neste caso, a Roménia corresponde a tal modelo político, 
uma vez que, em 1944, a União Soviética "ajudou" o povo romeno a libertar-se da ocupação alemã, mas com o preço da instauração no país da ideologia comunista soviética.

Esta circunstância, relativa ao passado político diferente dos dois países, junta-se a outras, igualmente distintas, nomeadamente o desnível socioeconómico existente entre os contextos culturais analisados, determinado, por um lado, pelos momentos diferentes de começo do regime democrático em ambos os países (1974, em Portugal, e 1989, na Roménia) e, por outro lado, pelo seu estatuto sociopolítico actual (Portugal está integrado na União Europeia, enquanto que a Roménia ainda é um país não comunitário), a par de um grau eventualmente distinto de adopção das normas do modelo de vida individualista, o que, na perspectiva de Hofstede (1980), implica um elevado Produto Nacional Bruto (PNB) e uma economia baseada em interesses individuais, em que o Estado não desempenha um papel dominante.

Destas considerações decorre a hipótese de que as normas do modelo de vida individualista têm sido assimiladas pela sociedade romena em menor grau do que pela sociedade portuguesa: como se pode observar, tal hipótese é sustentada por justificações de natureza política, económica e sociocultural, sendo ainda de referir que, a estas justificações, Ciochină e Faria (2006) acrescentam o facto de que também pode ser avançada uma justificação psicossocial, "relacionada com o facto de os actores sociais, quando confrontados com mudanças do contexto social em que vivem e agem, tenderem a manter as práticas sociais aprendidas, que, desta forma, continuam a influenciar as suas acções e interacções e, implicitamente, as próprias percepções das mesmas".

Assim, no que se refere à sociedade portuguesa, é de pressupor que, tendo a vantagem do tempo, quanto à instauração do regime democrático, bem como a vantagem dos benefícios económicos, pela adesão à comunidade europeia, já tenha assimilado melhor as normas do modelo de vida individualista, uma vez que, em muitos países, a tendência geral, num quadro de enriquecimento económico, é de mudança do colectivismo para o individualismo (Triandis, McCusker \& Hui, 1990).

A partir desta hipótese, de que a sociedade romena é mais colectivista do que a sociedade portuguesa, o que se pretende, no que se refere à relação entre estes dois tipos de cultura (individualista vs. colectivista) e as concepções pessoais de inteligência (estática vs. dinâmica), é pesquisar, no contexto escolar, a existência de um eventual padrão de associação entre estas dimensões, investigando, nomeadamente, se as CPI dinâmicas (que valorizam o papel do esforço e investimento, bem como o desenvolvimento da competência) caracterizam e são influenciadas por uma mentalidade mais individualista - que, segundo Hofstede (1980), prepara o indivíduo para ter uma atitude positiva face a situações novas e imprevistas, para aprender 
como aprender e para ser mais independente e autónomo -, e se as CPI estáticas (que salientam o evitamento do fracasso e dos desafios, a par da validação da competência pessoal) caracterizam e são influenciadas por uma mentalidade mais colectivista - que, segundo Hofstede (1980), prepara o indivíduo para aprender como fazer as coisas necessárias ao bom funcionamento de grupos de pertença e da sociedade, tornando menos visíveis e, até, menos valorizados os resultados e as atitudes de cada um.

No estudo anteriormente referido, realizado por Ciochină e Faria (2006), as autoras tinham como objectivo explorar as semelhanças e as diferenças entre Portugal e a Roménia, relativamente a esta dimensão de individualismo-colectivismo, indagando o seu impacto no contexto escolar, particularmente quanto ao desenvolvimento e às especificidades das concepções pessoais de inteligência. De referir, ainda, que as CPI foram avaliadas usando a Escala de Concepções Pessoais de Inteligência (ECPI) - ver Apêndice 1 -, construída e validada para a população portuguesa por Faria (2003): assim, sendo a primeira vez que a ECPI foi administrada nos dois contextos (português e romeno), a investigação referida começou por se centrar na validação do instrumento, através de estudos de análise factorial confirmatória (AFC), cujos resultados merecem ser explorados com uma amostra mais alargada e mais diversificada, particularmente do ponto de vista do nível socioeconómico.

Mais concretamente, após a AFC, a ECPI, com 26 itens (15 ilustrativos da concepção estática - saturando o factor designado estático - e 11 ilustrativos da concepção dinâmica - saturando o factor designado dinâmico), ficou reduzida a 13 itens (seis da concepção estática - itens $1,7,12,15,18$ e $22-\mathrm{e}$ sete da concepção dinâmica - itens $3,9,13,17,23,24$ e 26) em ambas as amostras, tendo sido necessária a eliminação dos restantes itens por revelarem baixas saturações nos respectivos factores de origem. Saliente-se que os itens eliminados relacionam o carácter estático ou dinâmico da inteligência com aspectos ligados ao sucesso, ao fracasso, aos desafios e às dificuldades, aspectos esses que nem sempre têm uma clara representação na mente dos alunos. Por sua vez, os itens que foram mantidos na escala salientam apenas o carácter estático ou dinâmico da inteligência e o facto de os indivíduos serem capazes de fazer algo a fim de desenvolver este atributo psicológico.

Assim, observa-se que, por agora, da administração da ECPI em dois contextos culturais distintos - português e romeno -, se destaca a possibilidade de se ter de vir a reconsiderar a sua estrutura factorial e, implicitamente, a realidade multifacetada das concepções pessoais de inteligência: no entanto, simultaneamente, saliente-se que poderá ser facilitada a obtenção de elementos acerca da sua relação com a dimensão cultural de individualismo-colectivismo, contribuindo-se, assim, para o esclarecimento do respectivo impacto e interacção estabelecidos com as CPI. 


\section{Conclusões finais: perspectivas futuras para a avaliação do IND/COL}

Nesta pesquisa, a par do estudo de validação da ECPI nos contextos culturais português e romeno, temos como objectivo testar e adoptar uma série de métodos e de técnicas complementares, com o apoio de novos instrumentos, a construir, para avaliar o IND/COL, no sentido de facilitar e promover uma compreensão mais aprofundada da fundamentação psicocultural das CPI.

Ora, apesar de Fiske (2002) considerar que as escalas utilizadas para avaliar o individualismo-colectivismo revelam características individuais mais do que culturais, logo, que os valores obtidos para uma característica não podem ser atribuídos à especificidade de uma cultura, a não ser que aquela característica seja considerada culturalmente construída e transmitida, tais escalas podem ser utilizadas com resultados satisfatórios se forem cuidadosamente construídas e administradas em conjunto com outros métodos complementares. Assim sendo, propomo-nos conceber um novo questionário, a partir dos já existentes, questionário esse que estará ligado à contextualização dos valores culturais subjacentes à dimensão de IND/COL, portanto, considerando que as amostras a serem investigadas são de adolescentes, os contextos envolvidos serão a família, a escola e os outros significativos.

Tal desiderato é importante, uma vez que alguns aspectos ilustrativos do colectivismo ou do individualismo podem perder a sua essência e relevância, em função da situação e do contexto exterior: a título exemplificativo, refira-se que uma pessoa pode sentir necessidade de pedir a opinião dos outros para tomar uma decisão sobre um problema que implica a sua família, enquanto que, no grupo de trabalho, pode preferir basear-se nas suas próprias ideias e modos de lidar com um determinado assunto, sem apelar a outros membros do grupo. Portanto, embora sejam principalmente trans-situacionais, como salienta Schwartz (1992), este tipo de valores, de crenças e de atitudes exprimem-se em contextos específicos, concretos e nas experiências diárias dos indivíduos, pelo que parece importante, nos questionários a utilizar, recorrer a uma apresentação mista de situações contextualizadas e descontextualizadas.

A este propósito, refira-se, ainda, que Shulruf, Hattie e Dixon (2003), ao analisarem o mesmo problema, ou seja, os contextos em que operam as atitudes, as crenças e os valores ligados ao IND/COL, salientam que o individualismo e o colectivismo podem ter expressões diferentes em diferentes contextos e situações, logo, propõem que, em vez de se solicitarem respostas ligadas à intensidade, se salientem respostas que captem a frequência de tais valores, crenças e atitudes, uma vez que se pode ser intenso em algumas situações, mas não em outras. Assim, a proposta dos três autores será 
tomada em consideração na construção futura de escalas que avaliem o IND/COL, no contexto português e romeno.

Mais ainda, neste domínio e na maioria dos estudos interculturais, têm sido utilizadas amostras apenas de estudantes, a partir das quais as culturas investigadas receberam uma caracterização na dimensão cultural IND/COL, portanto, outra preocupação futura será a de tentar incluir no estudo da influência do IND/COL nas CPI o grupo dos professores. Tal objectivo funda-se na justificação de que os valores, as crenças, as atitudes e as práticas educacionais dos professores modelam e influenciam o desenvolvimento psicossocial dos alunos, bem como as respectivas maneiras de estruturar os objectivos escolares e as concepções sobre diversos atributos pessoais.

Por fim, talvez a tarefa mais difícil seja a de testar e adoptar métodos e técnicas complementares mais adequados para avaliar o IND/COL. O enfoque será colocado na realização de entrevistas com especialistas de diferentes domínios (por exemplo, Psicologia, Sociologia e Antropologia), bem como com sujeitos leigos, de ambos os sexos e de diferentes idades e níveis socioeconómicos, para se obter uma melhor compreensão das especificidades da dimensão de IND/COL, tanto em Portugal como na Roménia.

Globalmente, além de questionários, seguindo o conselho de Fiske (2002) e o exemplo de Triandis et al. (1985, in Neto, 1995), será ainda proporcionado um interesse particular à construção de determinados cenários, solicitando-se aos sujeitos que terminem ou interpretem certas situações ilustrativas de comportamentos e atitudes individualistas ou colectivistas: de facto, estimulando a projecção psicológica dos sujeitos, tais cenários podem esclarecer aspectos culturais importantes, presentes a nível subconsciente nos indivíduos, aspectos estes que os questionários não conseguem captar.

Em suma, este investimento e desenvolvimento de métodos, técnicas e instrumentos tem como objectivo avaliar e validar o conteúdo teórico dos constructos de individualismo-colectivismo, bem como obter uma caracterização mais completa e aprofundada desta dimensão cultural, de tal modo que se possa evidenciar a existência de eventuais padrões de associação entre os aspectos positivos e negativos do IND/COL e das CPI para, em última instância, melhor conceber planos específicos de intervenção no contexto escolar, no sentido de fomentar a valorização dos aspectos positivos encontrados, promovendo concepções pessoais de inteligência mais adaptativas, logo, fomentando o desempenho, a mestria e o sucesso dos alunos nos dois países estudados. 


\section{Referências}

Bandura, M., \& Dweck, C. S. (1985). Self-conceptions and motivation: conceptions of intelligence, choice of achievement goals, and patterns of cognition, affect and behavior. Unpublished manuscript. Harvard University, Laboratory of Human Development.

Bond, M. H. (2002). Reclaiming the individual from Hofstede's ecological analysis - a 20-year odyssey: Comment on Oyserman et al. (2002). Psychological Bulletin, 128, 73-77.

Choi, I., \& Nisbett, R. E. (1998). Situational salience and cultural differences in the correspondence bias and the actor-observer bias. Personality and Social Psychology Bulletin, 24, 949-960.

Church, A. T., Ortiz, F. A., Katigbak, M. S., Avdeyeva, T. V., Emerson, A. M., Flores, J. J., \& Reyes, I. J. (2003). Measuring individual and cultural differences in implicit trait theories. Journal of Personality and Social Psychology, $85,332-347$.

Ciochină, L., \& Faria, L. (2006). Concepções pessoais de inteligência de estudantes portugueses e romenos: Estudo preliminar de análise factorial confirmatória. Psychologica, 41, 171-191.

Dweck, C. S. (1999). Self-theories: their role in motivation, personality, and achievement. Philadelphia, PA: Psychology Press.

Elliott, E. S., \& Dweck, C. S. (1988). Goals: an approach to motivation and achievement. Journal of Personality and Social Psychology, 54, 5-12.

Elliott, E. S., \& Harackiewicz, J. (1996). Approach and avoidance goals and intrinsic motivation: a mediational analysis. Journal of Personality and Social Psychology, 70, 461-475.

Faria, L. (1996). Desenvolvimento intra-individual das concepções pessoais de inteligência durante a adolescência. Revista Portuguesa de Psicologia, XXX (1), 17-33.

Faria, L. (2002). Teorias implícitas da inteligência. Paidéia, 12 (23), 93-103.

Faria, L. (2003). Escala de concepções pessoais de inteligência (E.C.P.I.). In M. M. Gonçalves, M. R. Simões, L. S. Almeida \& C. Machado (Coords.), Avaliação psicológica. Instrumentos validados para a população portuguesa (Vol. 1, pp. 131-144). Coimbra: Quarteto Editora.

Faria, L., Pepi, A., \& Alesi, M. (2004). Concepções pessoais de inteligência e auto-estima: Que diferenças entre estudantes portugueses e italianos?. Análise Psicológica, XXII (4), 43-60.

Fiske, A. P. (2002). Using individualism and collectivism to compare cultures - a critique of the validity and measurement of the constructs: comment on Oyserman et al. (2002). Psychological Bulletin, 128, 78-88.

Heine, S. J., Kitayama, S., \& Lehman, D. R. (2001). Cultural differences in self-evaluation: Japonese readily accept negative self-relevant information. Journal of Cross-Cultural Psychology, 32, 434-443. 
Heine, S. J., \& Lehman, D. R. (1995). Cultural variation in unrealistic optimism: Does the West feel more vulnerable than the East?. Journal of Personality and Social Psychology, 68, 595-607.

Henderson, B. B., Marx, H. M., \& Kim, Y. (1999). Academic interests and perceived competence in American, Japanese, and Korean children. Journal of Cross-Cultural Psychology, 30, 32-50.

Hofstede, G. (1980). Culture's consequences. Beverly Hills, CA: Sage.

Kapoor, S., Hughes, P. C., Baldwin, J. R., \& Blue, J. (2003). The relationship of individualism-collectivism and self-construal to communication styles in India and the United States. International Journal of International Relations, 27, 683-700.

Kitayama, S., Markus, H. R., Matsumoto, H., \& Norasakkunkit, V. (1997). Individual and collective processes in the construction of the self: self-enhancement in the United States and self-criticism in Japan. Journal of Personality and Social Psychology, 72, 1245-1267.

Miller, J. G. (1999). Cultural psychology: implications for basic psychological theory. Psychological Science, 10, 85-91.

Mugny, G., \& Carugati, F. (1985). L’intelligence au pluriel. Les représentations sociales de l'intelligence et de son développement. Cousset: Éditions Delval.

Neculau, A. (1996). Reprezentările sociale - dezvoltări actuale. In A. Neculau (Coord.), Psihologie socială. Aspecte contemporane (pp. 34-51). Iaşi: Editura Polirom.

Neto, F. (1995). Alocentrismo nos estudantes universitários. Revista Portuguesa de Pedagogia, XXIX (1), 21-36.

Oyserman, D., Coon, M. H., \& Kemmelmeier, M. (2002). Rethinking individualism and collectivism: evaluation of theoretical assumptions and meta-analyses. Psychological Bulletin, 128, 3-72.

Salili, F. (1994). Age, sex, and cultural differences in the meaning and the dimensions of achievement. Personality and Social Psychology Bulletin, 20, 635-648 .

Schwartz, S. H. (1992). Universals in the content and structure of values: Theoretical advances and empirical tests in 20 countries. In M. P. Zanna (Ed.), Advances in experimental social psychology (vol. 25, pp. 1-65). New York: Academic Press.

Shulruf, B., Hattie, J., \& Dixon, R. (2003). Development of a new measurement tool for Individualism and collectivism. Paper presented at the NZAREA/AARE Joint Conference 2003, Aucklund, New Zealand (http://www.aare.edu.au/03pap/ shu03265.pdf - site consultado: 14/03/2005, 11:35).

Somech, A. (2000). The independent and the dependent selves: different meanings in different cultures. International Journal of Intercultural Relations, 24, 161-172 .

Trafimow, D., Triandis, H. C., \& Goto, S. G. (1991). Some tests of the distinction between the private self and the collective self. Journal of Personality and Social Psychology, 60, 649-655. 
Triandis, H. C. (1994). Recherches récentes sur l'individualisme et le collectivisme. Les Cahiers Internationaux de Psychologie Sociale, 23, 14-27.

Triandis, H. C., Bontempo, R., Villareal, M. J., Asai, M., \& Lucca, N. (1988). Individualism and collectivism: Cross-cultural perspectives on self-ingroup relationships. Journal of Personality and Social Psychology, 54, 323-338.

Triandis, H. C., McCusker, C., \& Hui, C. H. (1990). Multimethod probes of individualism and collectivism. Journal of Personality and Social Psychology, 59, 1006-1020.

Vygotsky, L. S. (1978). Mind in society. The development of higher psychological processes. Harvard: President and Fellows of Harvard College. 


\section{Apêndice 1}

Itens da ECPI (Faria, 2003)

1. Tenho uma certa quantidade de inteligência e não posso fazer muito para a mudar. (E)

2. As dificuldades e os desafios que encontro impedem-me de desenvolver a minha inteligência. (E)

3. O esforço permite tornar-me mais inteligente. (D)

4. O que aprendo com as tarefas que faço é mais importante do que os resultados obtidos. (D)

5. Um mau resultado numa tarefa pode fazer os outros pensarem que sou pouco inteligente. (E)

6. Os erros que cometo podem ser uma oportunidade para desenvolver a minha inteligência. (D)

7. Por mais que me esforce, nunca conseguirei mudar a minha inteligência. (E)

8. A procura de novas soluções para resolver uma tarefa demonstra que não consigo dominá-la. (E)

9. Posso tornar-me mais inteligente se quiser. (D)

10. Realizar uma tarefa com sucesso permite-me mostrar aos outros que sou inteligente. (E)

11. Os desafios e as dificuldades que enfrento ajudam-me a desenvolver a minha inteligência. (D)

12. Posso aprender coisas novas, mas não posso realmente mudar a minha inteligência. (E)

13. Com esforço posso conseguir mudar a minha inteligência. (D)

14. A boa preparação para a realização de uma tarefa é um modo de provar aos outros que sou inteligente. (E)

15. Não posso aumentar a inteligência com que nasci. (E)

16. Quando me esforço mostro que sou pouco inteligente. (E)

17. Quando aprendo coisas novas a minha inteligência aumenta. (D)

18. Não sou tão inteligente quanto queria, mas não posso fazer muito para mudar isso. (E)

19. Conseguir bons resultados naquilo que faço é uma prova da minha inteligência. (E)

20. Devo evitar cometer erros, porque mostram que sou pouco inteligente. (E)

21. Realizar uma tarefa com sucesso permite desenvolver a minha inteligência. (D)

22. Não posso mudar muito a inteligência que possuo. (E) 
23. A boa preparação para a realização de uma tarefa é um modo de desenvolver a minha inteligência. (D)

24. A inteligência é algo que posso aumentar quanto quiser. (D)

25. Os resultados das tarefas que faço são mais importantes do que aquilo que aprendo. (E)

26. Posso fazer alguma coisa para mudar a minha inteligência. (D)

E - itens da concepção estática;

$\mathrm{D}$ - itens da concepção dinâmica.

A ECPI apenas poderá ser utilizada para fins de investigação e intervenção, após pedido formal à autora. 